\title{
Influence of Light and Temperature on the Extractability of Cerium(IV) as a Surrogate of Plutonium(IV) and its effect on the Simulation of an Accidental Fire in the PUREX Process.
}

Hervé Feuchter, ${ }^{a}$ Sylvain Duval, ${ }^{a,}{ }^{*}$ Christophe Volkringer, ${ }^{\mathrm{a}, \mathrm{b}}$, François-Xavier Ouf, ${ }^{\mathrm{c}}$ Laurence Rigollet, ${ }^{c}$ Laurent Cantrel, ${ }^{c}$ Matheus De Mendonca Andrade, ${ }^{c}$ François Salm ${ }^{\mathrm{c}}$, Claire Lavalette, ${ }^{\mathrm{d}}$ and Thierry Loiseau ${ }^{\mathrm{a}}$

${ }^{a}$ Université de Lille, CNRS, Centrale Lille, ENSCL, Univ. Artois, UMR 8181 - UCCS - Unité de Catalyse et Chimie du Solide, F-59000 Lille, France.

'Institut Universitaire de France (IUF), 1, rue Descartes, 75231 Paris cedex 05, France.

'Institut de Radioprotection et de Sûreté Nucléaire (IRSN), PSN-RES/SCA, PSN-

RES/SA2I, PSN-RES/SEREX, Gif-Sur-Yvette, 91192, France.

${ }^{d}$ Orano Cycle, 1 Place Jean Millier, 92400 Courbevoie, France.

* To whom correspondence should be addressed. E-mail: sylvain.duval@univ-lille.fr. Phone: (33) 320434 973, Fax: (33) 320434895.

To be submitted to ACS Omega

Version June 1, 2019 


\section{General Considerations}

Partition processes are typically best described by determining the partition coefficient $\mathrm{P}$ which is defined according to the equation:

$$
P=\frac{\gamma_{(\mathrm{org})}[\mathrm{X}]_{(\mathrm{org})}}{\gamma_{(\mathrm{aq})}[\mathrm{X}]_{(\mathrm{aq})}}
$$

Where $\gamma_{(\mathrm{org})}$ and $\gamma_{(\mathrm{aq})}$ are the activities of the analytes $\mathrm{X}$ in both organic and aqueous phases and $[\mathrm{X}]_{(\mathrm{org})}$ or $[\mathrm{X}]_{(\mathrm{aq})}$ their respective concentrations. Due to the complex nature of the species involved in the partition process of cerium and the difficulty in determining activity coefficients for each of them, we have calculated the distribution ratio. The distribution ratio $\mathrm{D}$ is defined as the concentration ratio of an analyte between two different phases. In our case, $\mathrm{D}$ can be defined as the concentration of cerium in the organic phase $\left(\left[\mathrm{Ce}^{3+}\right]_{(\mathrm{org})},\left[\mathrm{Ce}^{4+}\right]_{(\mathrm{org})}\right.$ ) divided by the concentration of cerium in the aqueous phase $\left(\left[\mathrm{Ce}^{3+}\right]_{(\mathrm{aq})},\left[\mathrm{Ce}^{4+}\right]_{(\mathrm{aq})}\right)$;

$$
\mathrm{D}_{\mathrm{Ce}}=\frac{\left[\mathrm{Ce}^{3+}\right]_{(\mathrm{org})}+\left[\mathrm{Ce}^{4+}\right]_{(\mathrm{org})}}{\left[\mathrm{Ce}^{3+}\right]_{(\mathrm{aq})}+\left[\mathrm{Ce}^{4+}\right]_{(\mathrm{aq})}}
$$

Since cerium(III) is not significantly extracted by TBP in the presence of a nitric acid phase, ${ }^{1,2}$ this equation can be simplified to:

$$
\mathrm{D}_{\mathrm{Ce}}=\frac{\left[\mathrm{Ce}^{4+}\right]_{(\mathrm{org})}}{\left[\mathrm{Ce}^{3+}\right]_{(\mathrm{aq})}+\left[\mathrm{Ce}^{4+}\right]_{(\mathrm{aq})}}
$$

This equation was used to calculate distribution ratios, along with cerium content analysis by spectrophotometry with Arsenazo-III.

Extraction yield is expressed as the ratio of moles of extracted cerium $\left(\mathrm{n}_{\mathrm{Ce} \text { org }}\right)$ divided by the total number of cerium moles $\left(\mathrm{n}_{\mathrm{Ce} \text { total }}\right)$ :

$$
\begin{gathered}
\% \mathrm{Ce}=\frac{\mathrm{n}_{\text {Ce org }}}{\mathrm{n}_{\text {Ce total }}} \times 100 \\
\% \mathrm{Ce}=\frac{[\mathrm{Ce}]_{(\text {org })} \mathrm{V}_{\text {org }}}{[\mathrm{Ce}]_{(\text {org })} \mathrm{V}_{\text {org }}+[\mathrm{Ce}]_{(\mathrm{aq})} \mathrm{V}_{\mathrm{aq}}} \times 100
\end{gathered}
$$

$[\mathrm{Ce}]_{(\text {org })},[\mathrm{Ce}]_{(\mathrm{aq})}$ are cerium concentrations in volumes $\mathrm{V}_{\text {org }}$ and $\mathrm{V}_{\mathrm{a}} \mathrm{q}$ of respectively organic and aqueous phases.

Since $\mathrm{V}_{\text {org }}=\mathrm{V}_{\mathrm{aq}}$, the yield can be expressed as: 


$$
\% \mathrm{Ce}=\frac{[\mathrm{Ce}]_{(\mathrm{org})}}{[\mathrm{Ce}]_{(\mathrm{org})}+[\mathrm{Ce}]_{(\mathrm{aq})}} \times 100
$$

\section{Procedure of Data Fitting of kinetic experiments}

Experimental kinetic data was fitted to a fractional order (0.5) which gave the best results compared to zero, first or second order fitting. The following equation was used, where $\mathrm{k}$ is the apparent rate constant, $\mathrm{C}$ the cerium(IV) concentration at time $\mathrm{t}$ and $\mathrm{C}_{0}$ the initial cerium(IV) concentration:

$$
\begin{gathered}
-\frac{d C}{d t}=k \sqrt{C} \\
\int \frac{1}{\sqrt{C}} d C=-\int k d t \\
2 \sqrt{C}(t)+\text { constant }=-k t+\text { constant }
\end{gathered}
$$

At $\mathrm{t}=0 \mathrm{~s}, \sqrt{ } \mathrm{C}=\sqrt{ } \mathrm{C}_{0}:$

$$
\sqrt{\mathrm{C}}(\mathrm{t})=-\frac{1}{2} \mathrm{kt}+\sqrt{\mathrm{C}_{0}}
$$

Which can also be expressed accordingly:

$$
\frac{\sqrt{\mathrm{C}}(\mathrm{t})}{\sqrt{\mathrm{C}_{0}}}=-\frac{1}{2 \sqrt{\mathrm{C}_{0}}} \mathrm{kt}+1
$$

Absorbance of the cerium complex can be expressed as:

$$
\begin{aligned}
\mathrm{A}_{0} & =\varepsilon_{\mathrm{Ce}} \mathrm{lC}_{0} \\
\mathrm{~A} & =\varepsilon_{\mathrm{Ce}} \mathrm{lC}
\end{aligned}
$$

$\varepsilon_{\mathrm{Ce}}$ and 1 stand for the molar absorption coefficient of the cerium complex and the length of the vial respectively.

Therefore:

$$
\frac{\sqrt{\mathrm{A}}(\mathrm{t})}{\sqrt{\mathrm{A}_{0}}}=-\frac{1}{2 \sqrt{\mathrm{A}_{0}}} \mathrm{kt}+1
$$

Experimental data was fitted by plotting $\sqrt{ } \mathrm{A} /{ } \mathrm{A}_{0}$ as a function of time and linear regression thereof to determine $k$ value. 


\section{Supplementary Information Figures:}

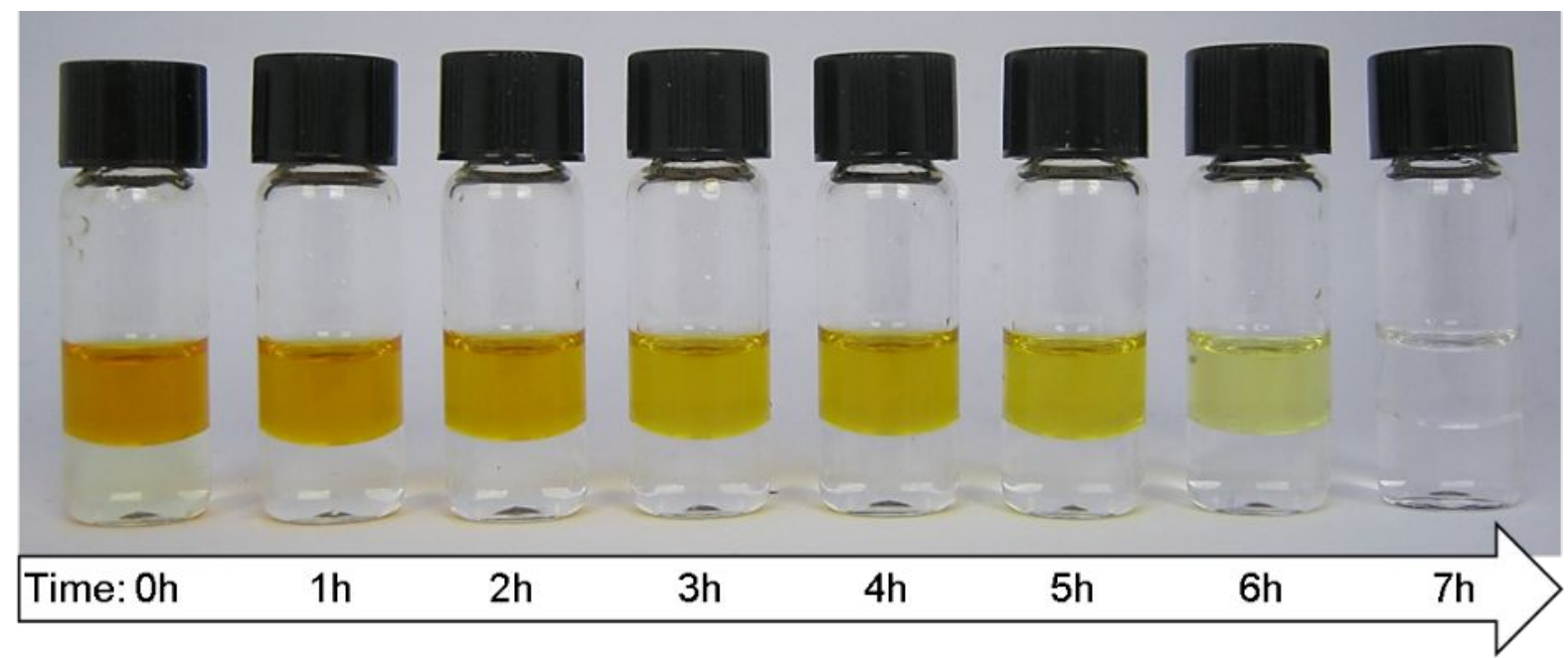

Figure S1: Evolution of the color of the biphasic medium mixture at different time intervals in the presence of light at $18^{\circ} \mathrm{C}$. The upper phase is the organic mixture of TBP and HTP while the lower phase is the aqueous nitric acid phase.

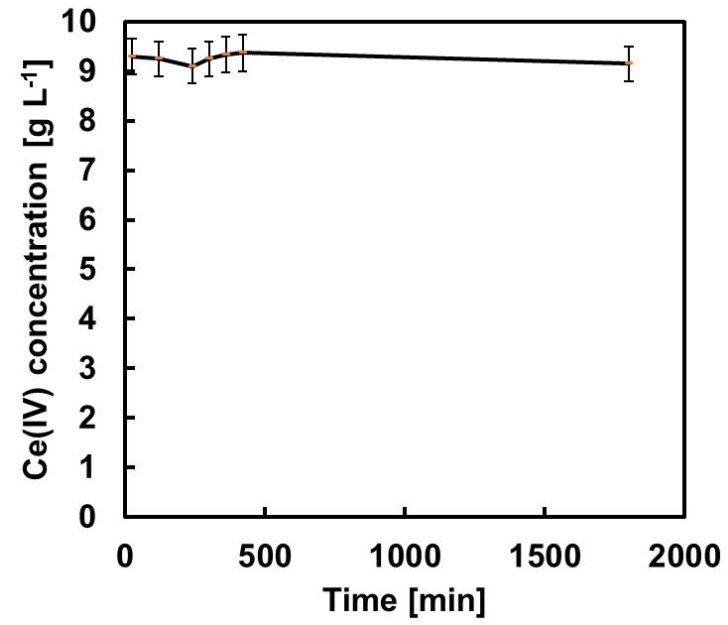

Figure S2: Evolution of cerium(IV) concentration as a function of time at $70^{\circ} \mathrm{C}$ in 4 mol.L ${ }^{-1}$ nitric acid. 


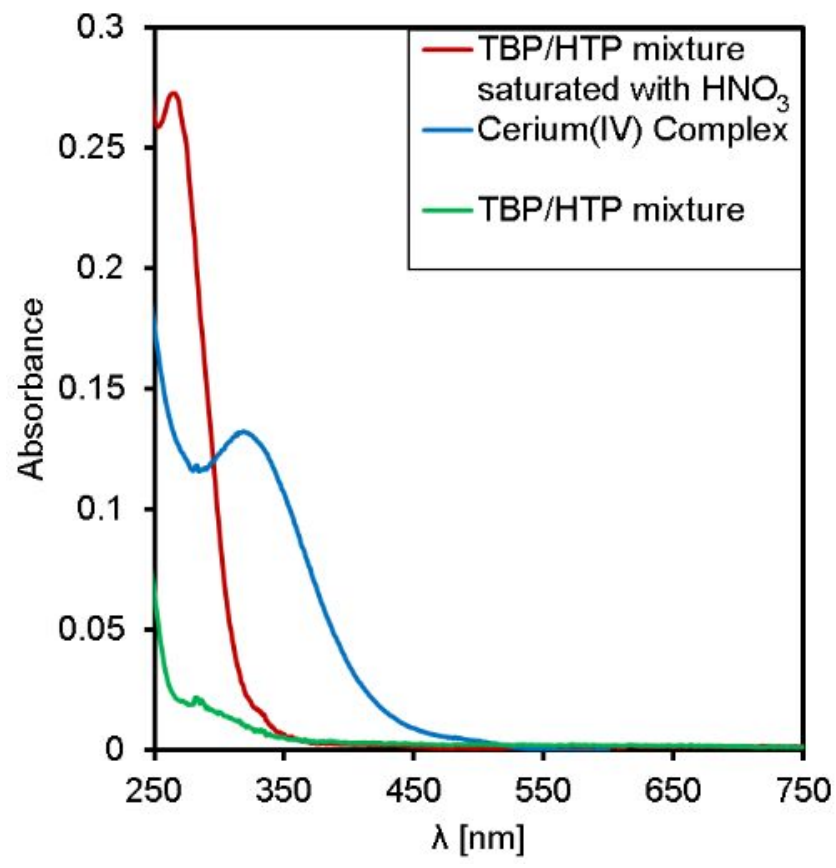

Figure S3: UV-Visible spectra of TBP/HTP mixture (green), TBP/HTP mixture saturated with $\mathrm{HNO}_{3}$ and water (red) and $\mathrm{Ce}(\mathrm{IV})-\mathrm{NO}_{3}-\mathrm{TBP}_{(\text {org) }}$ complexes in TBP/HTP mixture saturated with $\mathrm{HNO}_{3}$ and water (blue), at $25^{\circ} \mathrm{C}$.

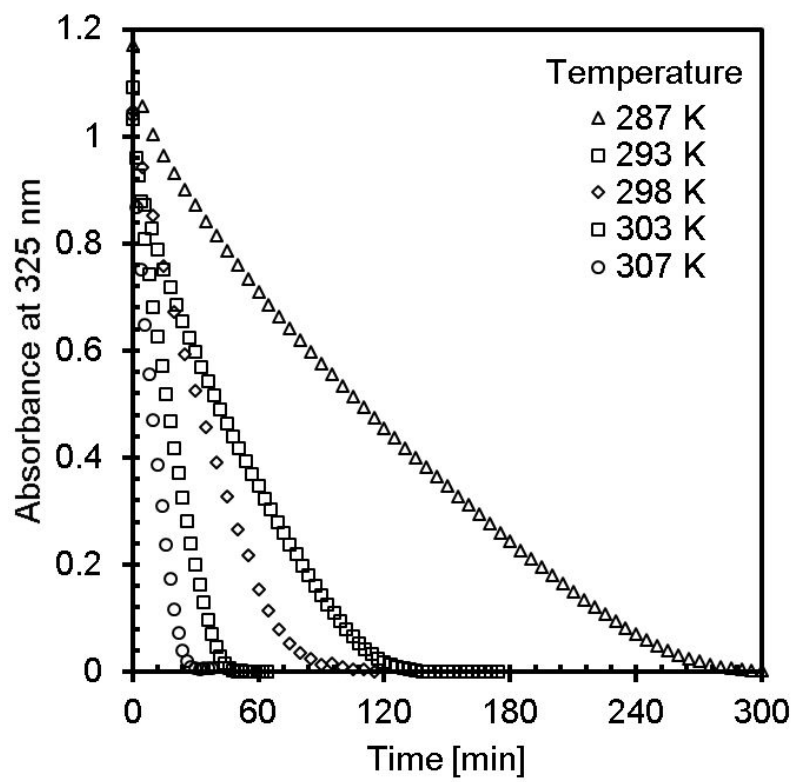

Figure S4: Experimental data of the cerium(IV) complex absorbance at $325 \mathrm{~nm}$ as a function of time at various temperatures. 


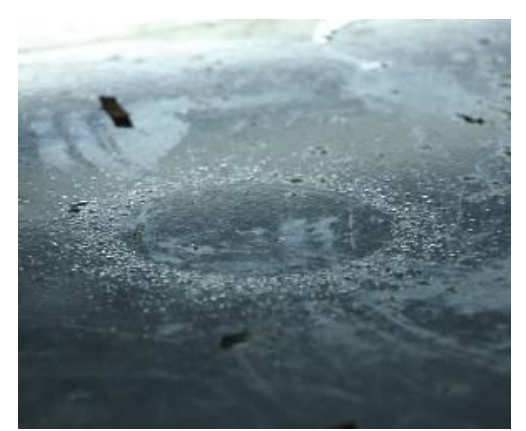

a)

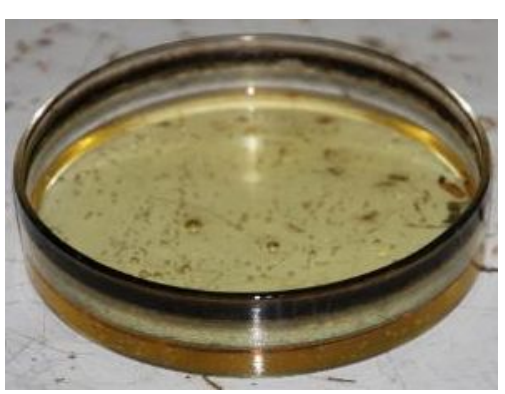

b)

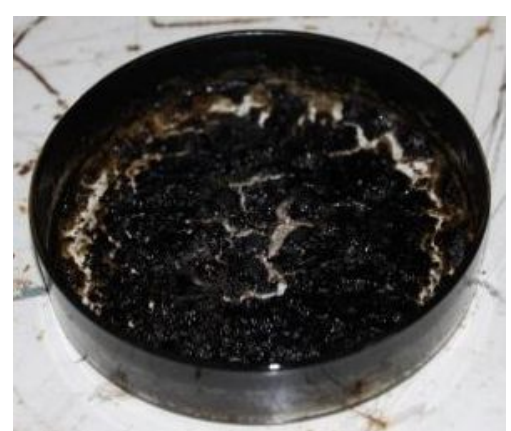

c)

Figure S5: Still images of a) liquid projections around the base of the container after combustion, b) combustion medium at the end of a biphasic fire experiment c) combustion medium at the end of the monophasic fire experiment.

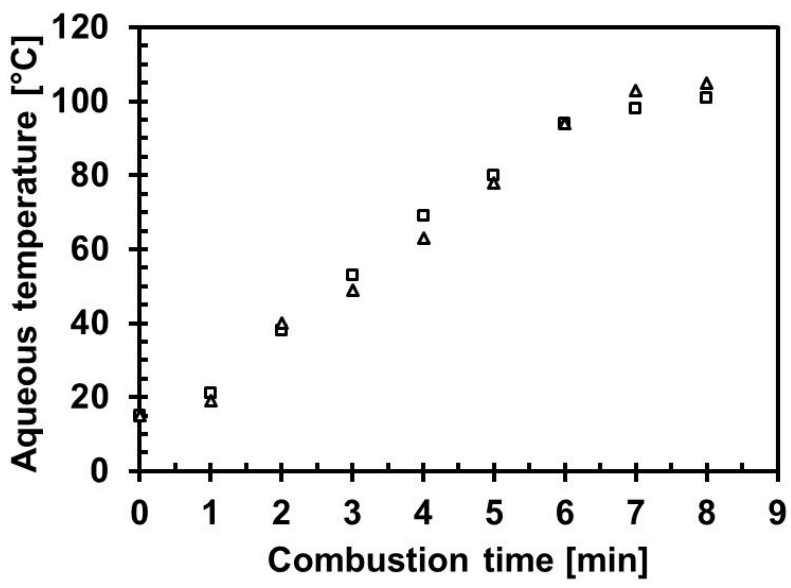

Figure S6: Evolution of the temperature of the aqueous phase in a biphasic fire as a function of time. Two experiments have been carried out to confirm replicability.

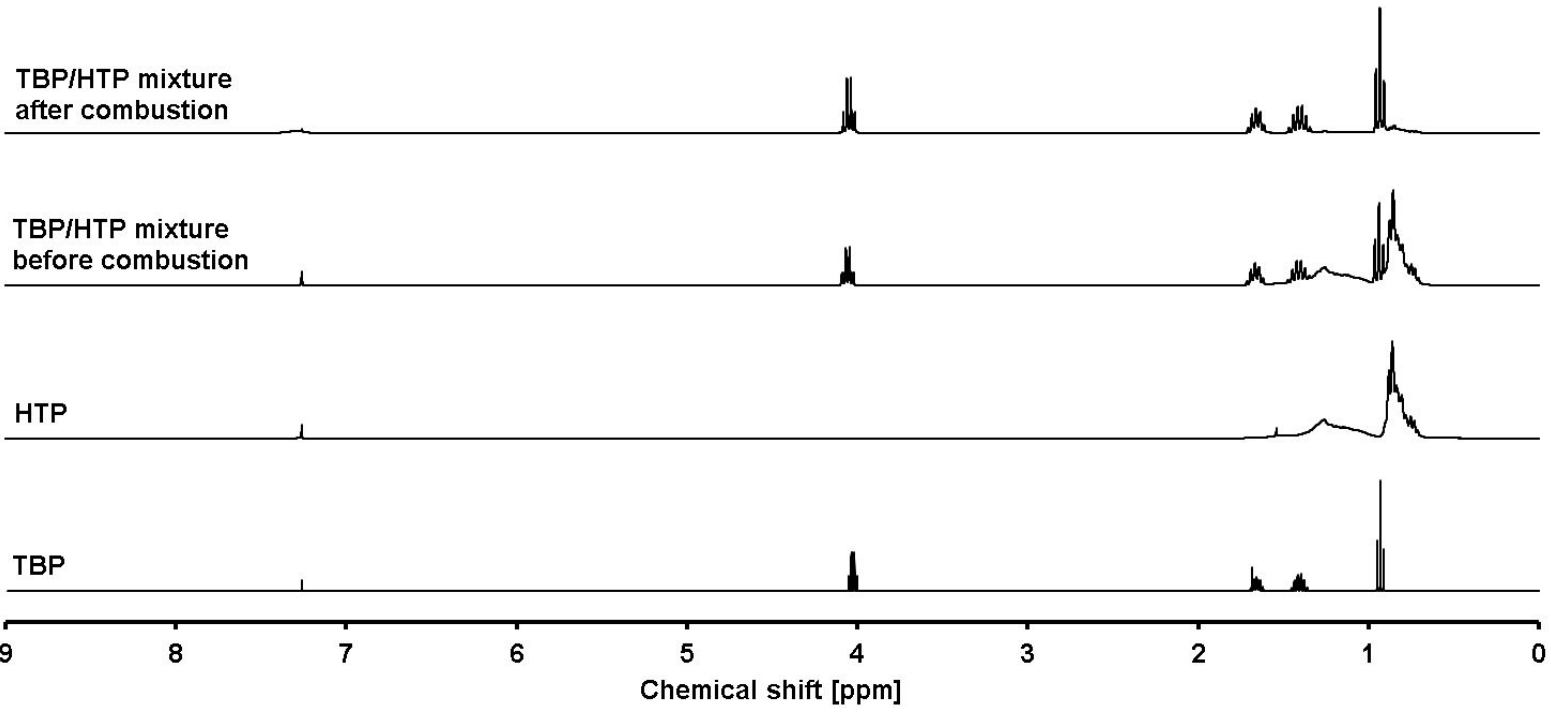

Figure S7: ${ }^{1} \mathrm{H}$ NMR $\left(\mathrm{CDCl}_{3}\right)$ spectra of TBP, HTP, TBP/HTP mixture before combustion and TBP/HTP after combustion. 


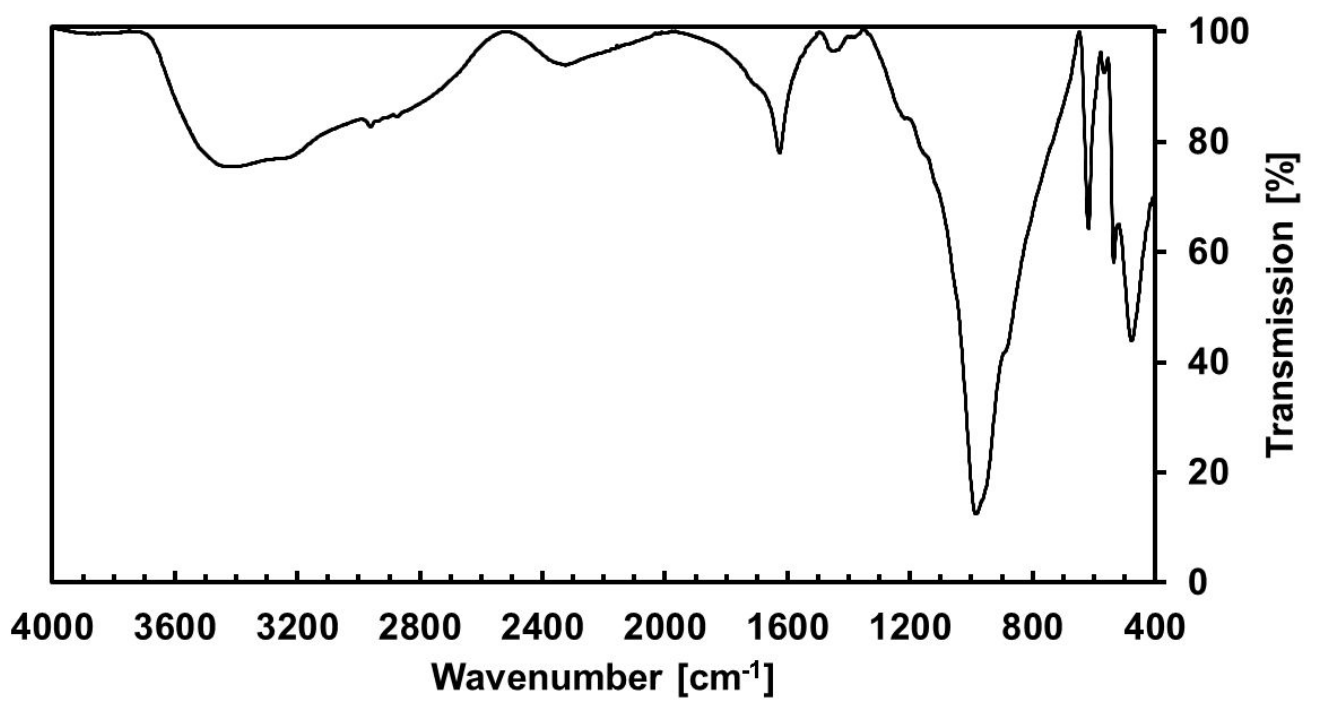

Figure S8: Infrared spectrum of a combustion soot sample.

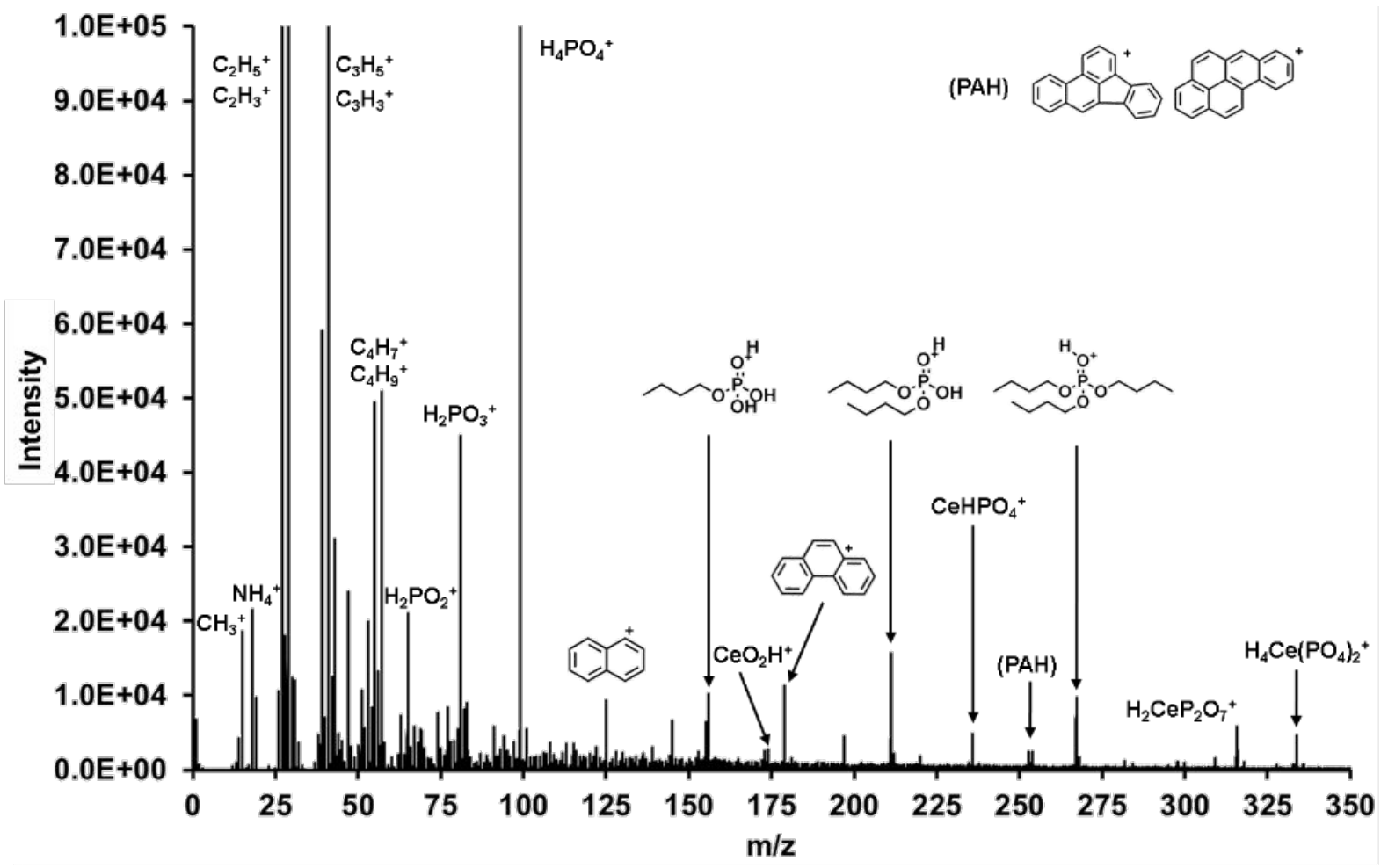

Figure S9: Positive mass spectrum of soot particles. 


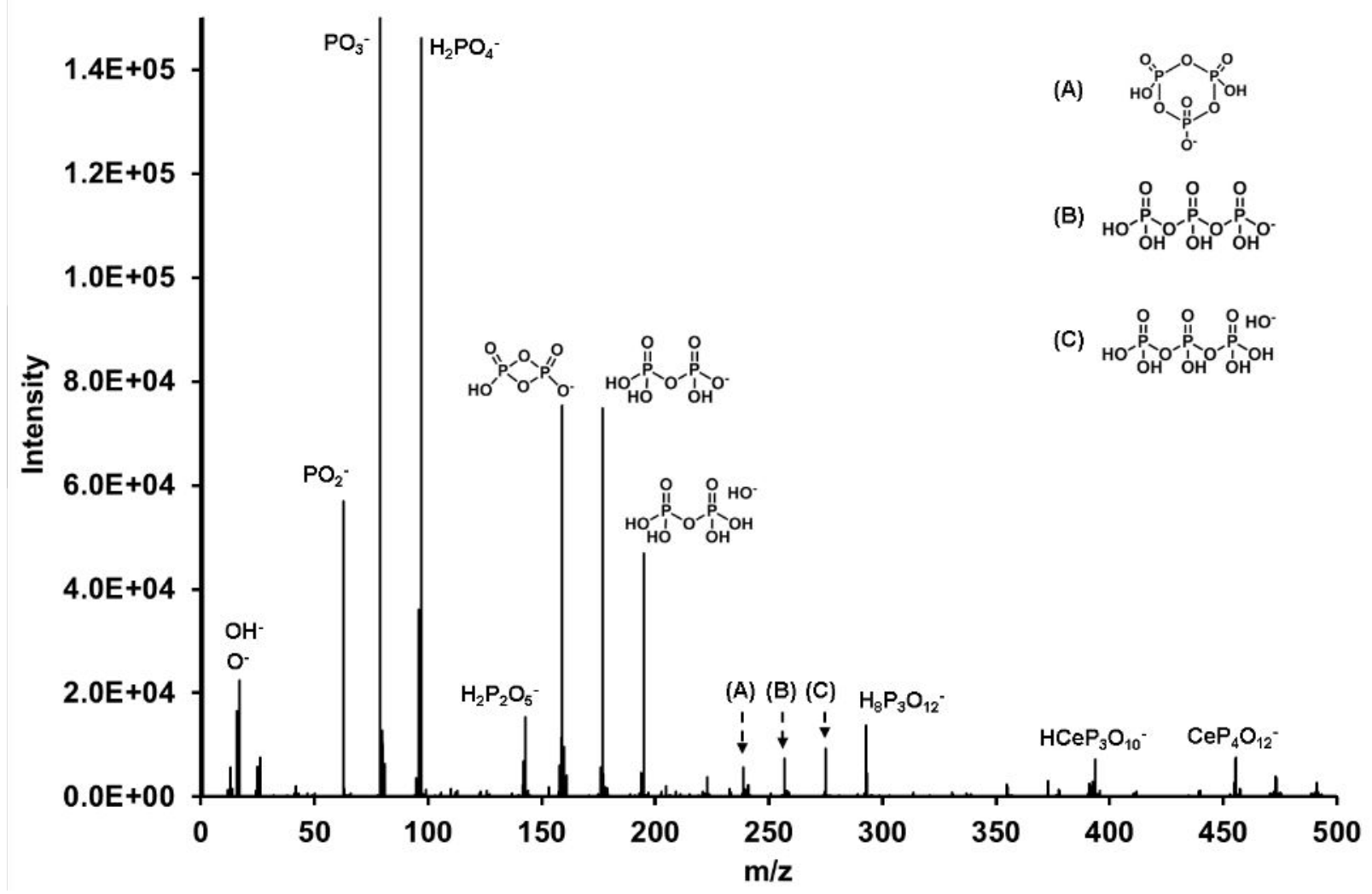

Figure S10: Negative mass spectrum of soot particles. 